\title{
Численное моделирование сенсоров на основе линейных металлических решеток
}

\author{
О.Э. Камешков ${ }^{1,2}$, В.В. Герасимов ${ }^{1,2}$, Б.А.Князев ${ }^{1,2}$ \\ ${ }^{1}$ Новосибирский государственный университет, Новосибирск, 630090, Пирогова 2 \\ ${ }^{2}$ Институт ядерной физики им. Будкера, Новосибирск, 630090, проспект Ак. Лаврентьева, д. 11 \\ тел: +7 (905) 950-57-90, эл. почта: o.kameshkov@g.nsu.ru
}

DOI 10.34077/RCSP2021-85

Быстрые и высокочувствительные сенсоры на основе поверхностного плазмонного резонанса (ППР) - это хорошо зарекомендовавшая себя технология измерения показателя преломления и спектров веществ в оптическом диапазоне. В их основе лежит возбуждение поверхностных плазмонполяритонов в схеме Кретчмана на тонких металлических пленках, поверх которых нанесена некая биологическая субстанция. Поверхностный плазмон можно рассматривать как связанную затухающую волну, распространяющуюся вдоль границы раздела металл-диэлектрик. Электрическое поле экспоненциально затухает перпендикулярно плоскости, обеспечивая высокую чувствительность поверхности к изменениям в ее окрестности.

Терагерцовое (ТГц) излучение является неионизирующим и неразрушающим биологические объекты. Кроме того, энергия фотонов соответствует вращательным и колебательным модам большого числа сложных молекул, что дает уникальные спектры поглощения. Как следствие, многие биологические вещества могут быть обнаружены в ТГц диапазоне, и это делает терагерцовую спектроскопию перспективным инструментом для биологических исследований [1].

Для регистрации малых концентраций веществ и обнаружения небольших изменений в диэлектрической среде необходимы высокая концентрация электромагнитного поля и узкие пики в спектрах. Обнаружение молекул в ТГц диапазоне с использованием ППР на тонких металлических пленках ограничено из-за высоких значений оптических констант металлов. Однако использование резонанса поверхностных спуф-плазмонов на структурированных металлических поверхностях и ППР на металлических дифракционных решетках позволяют реализовать высокочувствительные сенсоры в случае металлов с высокой проводимостью в ТГц диапазоне [2-3].

В данной работе проводилось сравнение методом численного моделирования сенсорных возможностей одномерных дифракционных и субволновых решеток. Оптимизированная дифракционная решетка представляет перспективный, недорогой и простой в изготовлении ТГц датчик показателя преломления [4]. Мы численно исследовали влияние периода решетки, глубины решетки и показателя преломления на ППР-свойства решетки. Одномерные субволновые металлические прямоугольные решетки исследовались в схеме нарушенного полного внутреннего отражения (конфигурация Отто), которая используется для удовлетворения условий фазового синхронизма. Выполнен параметрический анализ данной сенсорной системы.

Работа выполнена при поддержке гранта РНФ 19-12-00103. Расчеты выполнялись с использованием оборудования ЦКП «СЦСТИ» на базе УНУ "Новосибирский ЛСЭ" в ИЯФ СО РАН.

\section{Лuтература}

[1] M. Naftaly, N. Vieweg, and A. Deninger. Sensors, 19, 4203 (2019).

[2] A. Sathukarn, S. Boonruang, S. Horprathum et.al. International Journal of optics (2020).

[3] V.V. Gerasimov et al, AIP Conf. Proc. 2299, 030013-1-030013-9 (2020).

[4] O.E. Kameshkov, V.V. Gerasimov and B.A. Knyazev, AIP Conf. Proc, 2299, 1, 030012 (2020) 